\title{
A teoria cognitiva da aprendizagem multimídia no desenvolvimento de atividades de alfabetização matemática
}

The cognitive theory of multimedia learning in the development of mathematical literacy activities

\author{
A. N. Braga ${ }^{1 *}$; D. T. Alves ${ }^{1,2}$; S. C. Pereira Filho ${ }^{3}$; N. P. C. Souza ${ }^{4}$ \\ ${ }^{1}$ Programa de Pós-Graduação em Docência em Educação em Ciências e Matemática, Instituto de Educação \\ Matemática e Científica, Universidade Federal do Pará, 66075-110, Belém-Pará, Brasil \\ ${ }^{2}$ Faculdade de Física, Universidade Federal do Pará, 66075-110, Belém-Pará, Brasil \\ ${ }^{3}$ Faculdade de Ciências Naturais, Universidade Federal do Pará - Campus de Breves, 68800-000, Breves-Pará, Brasil \\ ${ }^{4}$ Escola de Aplicação da Universidade Federal do Pará,66095-780, Belém-Pará, Brasil
}

*alinensbraga@gmail.com

(Recebido em 14 de fevereiro de 2019; aceito em 07 de maio de 2019)

\begin{abstract}
$\overline{\text { Este trabalho tem como objetivo discutir a importância do uso dos canais auditivo e visual no contexto da }}$ elaboração de materiais didáticos e atividades para sala de aula, voltados à alfabetização matemática. A metodologia consistiu na revisão de literatura de diversos trabalhos relacionados à Teoria Cognitiva da Aprendizagem Multimídia, visando destacar a aplicação dos princípios dessa teoria na apresentação de atividades de alfabetização matemática comumente usadas em sala de aula.
\end{abstract}

Palavras-chave: Alfabetização Matemática, Aprendizagem Multimídia, Princípios da Teoria Cognitiva de Aprendizagem Multimídia.

In this article, we aim to discuss the importance of the use of auditory and visual channels in the context of the elaboration of didactic materials and activities for students in classroom, focusing on mathematical literacy. The methodology used by us consisted of a literature review of several works related to the Cognitive Theory of Multimedia Learning, highlighting the application of the principles of this theory in the presentation of mathematical literacy activities commonly used in classrooms.

Keywords: Mathematical Literacy, Multimedia Learning, Principles of Cognitive Theory of Multimedia Learning.

\section{INTRODUÇÃO}

A Teoria Cognitiva da Aprendizagem Multimídia (TCAM) pressupõe que o sistema humano de processamento de informações é composto pelos canais visual/pictórico e auditivo/verbal, os quais possuem capacidade limitada de processamento. Desse modo, a aprendizagem humana se dá a partir de um processo ativo que compreende a atenção às informações relevantes, a organização mental das informações selecionadas e, por fim, a associação destas informações aos aprendizados prévios. Santos e Tarouco (2007) [1] afirmam que entender o processo cognitivo humano é compreender de que forma "os seres humanos percebem, processam, codificam, estocam, recuperam e utilizam as informações". Assim, a compreensão de como estes sistemas cognitivos lidam com a informação pode ter grande importância para o processo de aprendizagem, pois permite a disposição dessa informação - necessária à aprendizagem - de modo mais adequado ao seu processamento.

De acordo com Baddeley et al. (2009) [2], a estrutura cognitiva é composta de um sistema de memórias, que consiste em: memória sensorial, memória de curta duração, memória de longa duração e memória de trabalho. A memória sensorial é a responsável pelo primeiro acesso das informações à estrutura cognitiva, funcionando como área de conexão na percepção dos estímulos (visuais, auditivos, gustativos, olfativos e táteis) recebidos pelos sentidos. Embora a memória sensorial possua uma capacidade relativamente grande em captar os estímulos, não possui o mesmo potencial para armazená-los, retendo as informações por um período muito pequeno. A memória de curta duração é a memória responsável por armazenar pequenas quantidades de informações por 
um período curto. A memória de longo prazo, de acordo com Feldman (2015) [3], funciona como um repositório de capacidade quase ilimitada, onde as informações armazenadas encontram-se estruturadas em esquemas organizados de forma coerente para que possam ser acessados quando necessário.

A memória de trabalho, conforme Souza (2010) [4], é compreendida como o eixo do processo ativo da mente humana, sendo responsável por processar e armazenar as informações recebidas pela memória sensorial e associá-las às informações já armazenadas na memória de longo prazo. Para Miller (1994) [5], a memória de trabalho possui uma capacidade de armazenamento limitada, sendo capaz de processar simultaneamente, no máximo, de 5 a 9 itens. Quando excedido esse limite, ocorre um decaimento no seu desempenho em lidar com as informações recebidas pela memória sensorial.

Assim, uma vez que o sistema cognitivo humano é composto por um conjunto de memórias que interagem entre si para armazenar e processar as informações percebidas no ambiente, em qualquer processo de ensino é, então, necessário que o professor leve em conta essa capacidade limitada da memória de trabalho dos estudantes durante as atividades desenvolvidas em sala, para que sobrecargas nessa memória não gerem prejuízo à aprendizagem.

\subsection{A Aprendizagem Multimídia}

De acordo com Mayer (2009) [6], dentre as diferentes ferramentas pedagógicas utilizadas em sala de aula, os recursos multimídia tornam-se uma alternativa interessante para melhorar a aprendizagem, tendo em vista que podem fazer uso de estímulos visuais e auditivos. O termo multimídia é aqui compreendido como um conjunto de diversos meios técnicos, com o objetivo de apresentar as informações de diversas formas e por meio de diferentes modalidades sensoriais. Desse modo, o recurso multimídia pode ser percebido em três níveis distintos: (i) nível técnico vinculado às ferramentas que são condutoras de sinais, como computadores, redes, monitores, entre outros; (ii) nível semiótico - relacionado à forma de apresentação desses sinais, como textos, imagens e sons e; (iii) nível sensorial - vinculado ao tipo de modalidade de recebimento de sinais, visual ou auditiva.

Estes três níveis do recurso multimídia tem um interessante desdobramento na sala de aula. Nesse contexto, professor envia sistematicamente informações aos seus alunos, o que o caracteriza como um elemento condutor de sinal, atuando no nível técnico dos recursos multimídia. Ao utilizar o quadro da sala de aula, professor e quadro são os condutores de sinais, atuando também no nível técnico. Já a forma como o professor apresenta as ideias ou informações - seja verbalmente usando sua própria voz ou visualmente apresentando textos e figuras no quadro - corresponde ao nível semiótico da aula. Estas informações apresentadas verbalmente ou visualmente serão recebidas pelos estudantes através dos canais visual ou auditivo, representando o nível sensorial dos recursos multimídia.

De acordo com Schnotz e Lowe (2003) [7], percebe-se que muitos educadores têm dificuldade em distinguir esses níveis do recurso multimídia, associando esse recurso, em grande parte das vezes, apenas ao nível técnico, isto é, às ferramentas condutoras de sinais. Entretanto, é válido destacar que, além das ferramentas condutoras de sinais, os outros dois níveis - o semiótico e o sensorial - são igualmente relevantes e precisam ser levados em conta no processo educacional, uma vez que impactam diretamente o processamento da informação. Por exemplo, diversas ferramentas multimídia voltadas ao ensino, apesar de possuírem a possibilidade de utilização de ambos os canais semióticos/sensoriais (visual ou auditivo), utilizam majoritariamente apenas um dos canais, por exemplo, apresentando textos escritos e imagens simultaneamente, o que pode prejudicar a aprendizagem devido à sobrecarga da memória de trabalho, como veremos na seção seguinte.

A compreensão desta questão motivou o desenvolvimento de materiais multimídia mais elaborados, que buscam aproveitar os diferentes recursos que estas ferramentas oferecem, de modo a melhorar a aprendizagem, de acordo com Schnotz e Lowe (2003) [7]. 


\subsection{Teoria da Carga Cognitiva}

Conforme Sweller et al. (2011) [8], cada material instrucional com o qual os estudantes aprendem irá exigir uma determinada carga cognitiva para que ocorra a aprendizagem, sendo que esta carga cognitiva irá depender também do design instrucional do referido material. Estas cargas cognitivas podem ser classificadas em três tipos:

- Carga cognitiva extrínseca ou estranha: é a carga cognitiva que não colabora para a construção de esquemas cognitivos. Esta ocorre devido ao acúmulo de um design instrucional fraco, que não está relacionado ao propósito formativo.

- Carga cognitiva intrínseca ou essencial: é a carga cognitiva vinculada à complexidade do conteúdo do material pedagógico, ou seja, é o exercício mental realizado pelo estudante devido à dificuldade imposta pelo próprio tema abordado no material instrucional.

- Carga cognitiva relevante ou generativa: é a carga cognitiva que oferece sentido para o recurso instrucional, ou seja, o exercício mental torna-se produtivo devido à aquisição de informações relevantes, que oferecem a possibilidade de construção de esquemas mentais mais complexos, tornando a aprendizagem relevante.

A carga cognitiva do material instrucional não seria um problema se não houvesse a limitação da capacidade cognitiva humana, conforme descrito anteriormente. Neste sentido, de acordo com Mayer (2009) [6], existem três aspectos a serem considerados quando discorremos sobre aprendizagem por meio de materiais instrucionais:

1. A cognição humana é constituída de dois canais diferentes para o processamento das informações: o canal visual e o canal auditivo;

2. A memória humana possui uma capacidade limitada de processamento de informação em ambos os canais;

3. O processo formativo só ocorrerá quando houver processamento cognitivo essencial, no que se refere às informações oriundas dos dois canais, auditivo e visual.

Nesse sentido, Mayer (2009) [6] afirma, no contexto da Teoria Cognitiva da Aprendizagem Multimídia (TCAM), que os materiais instrucionais multimídia são recursos excelentes para a prática docente, tendo em vista que neste tipo de ferramenta é possível utilizar os dois principais canais de processamento de informação (o visual e o auditivo), com o intuito de não sobrecarregar somente uma via de captação de informação. Entretanto, para Mayer, o uso dos dois canais não garante que a sobrecarga não ocorra, pois isto está vinculado às formas como os dois canais são utilizados.

\subsection{Teoria Cognitiva da Aprendizagem Multimídia}

Mayer (2009) [6], através da TCAM, propõe princípios para a construção e uso de recursos multimídia em educação visando melhorar a aprendizagem ao levar em consideração a capacidade limitada dos canais auditivo e visual no processamento ativo, bem como a sistematização e correlação com conhecimentos prévios das informações consideradas relevantes.

O processamento cognitivo é concluído quando o indivíduo consegue construir um modelo mental da informação que lhe foi apresentada. A TCAM define cinco processos que estão vinculados à construção de um modelo mental, os quais devem ser considerados na elaboração das mensagens educacionais multimídia, segundo Mayer (2009) [6]:

- Seleção das palavras importantes no texto ou narrativas que são exibidas;

- Seleção das imagens importantes das ilustrações exibidas;

- Sistematização das palavras selecionadas em um modelo verbal coerente;

- Sistematização das imagens selecionadas em um modelo pictórico coerente;

- Associação dos modelos pictóricos e verbais a conhecimentos prévios.

De acordo com Mayer (2009) [6], para processar as palavras faladas, os sons das palavras, captados pelos ouvidos, são levados à memória auditiva sensorial, onde ficam armazenados provisoriamente. Depois disso, o processo cognitivo ativo ocorre conforme a atenção é dada ao 
som, e somente depois é possível correlacionar o som com imagens e então desenvolver, de forma coerente, modelos mentais e associá-los a outros prévios. De modo similar, o processamento visual se dá quando as imagens são captadas pelos olhos e levadas à memória sensorial visual, onde ficam armazenadas por um tempo curto, e em seguida o processamento ativo começa e as informações visuais são organizadas em estruturas coerentes que deverão ser associadas posteriormente a conhecimentos prévios.

Nesse sentido, no caso de palavras apresentadas visualmente (palavras impressas), estas são inicialmente processadas como uma informação visual. Em seguida, ao serem pronunciadas mentalmente, as palavras podem ser processadas como uma informação verbal. No momento em que as palavras escritas são capturadas pelo canal visual, como ocorre durante a leitura de um livro, estas seguem direções variadas na organização lógica e coerente de informações relevantes.

Ao levar-se em conta a ideia de equilíbrio de cargas entre os canais visual e auditivo, conforme Mayer (2009) [6], algumas combinações destas cargas podem ser mais indicadas do que outras para fins didáticos. Para compreendermos quais combinações seriam mais indicadas, utilizamos, no presente trabalho, os princípios da TCAM, os quais visam melhorar a sistematização das informações entre os canais auditivo e visual a fim de que a aprendizagem por meio de materiais multimídia seja mais eficiente. Nessa perspectiva, Mayer (2009) [6] propôs doze princípios para embasar a construção de ferramentas multimídia, além da organização para a prática pedagógica do uso das mesmas. Assim, o presente trabalho enfoca em como aplicar os princípios da TCAM no desenvolvimento de atividades de alfabetização matemática. Na tentativa de discutir essa aplicação, o presente trabalho foca em apresentar ao leitor como é possível aplicar os conhecimentos da TCAM na apresentação de atividades comuns de alfabetização matemática, usadas em sala de aula.

\section{MATERIAL E MÉTODOS}

O presente trabalho propõe-se a descrever como os princípios da TCAM, de acordo com Mayer (2009) [6] podem contribuir no desenvolvimento de atividades comuns utilizadas em sala de aula, voltadas à alfabetização matemática.

Para tanto, foram utilizadas, em nossa exemplificação, atividades relacionadas à alfabetização matemática de acordo com os seguintes critérios:

1. Serem típicas e de fácil utilização em sala de aula;

2. Apresentarem, prioritariamente, o suporte escrito.

Após a apresentação das atividades, as mesmas foram analisadas com base nos princípios da TCAM. Desse modo, foi possível identificar que, dependendo de como os estímulos visuais e auditivos propostos nas atividades são apresentados pelo professor, as mesmas podem gerar maior ou menor carga cognitiva.

\section{RESULTADOS E DISCUSSÃO}

A alfabetização matemática é fundamental para o desenvolvimento da criança, tendo em vista que é nos anos iniciais do Ensino Fundamental que a criança desenvolve as noções iniciais de diversas áreas do conhecimento. Para Souza (2010) [4], a forma como os conhecimentos são abordados em sala de aula irá definir se os alunos conseguirão ou não um bom desempenho no seu processo formativo em níveis mais elevados de ensino. Neste sentido, torna-se fundamental desenvolver atividades multimídia de alfabetização matemática levando em conta os processos cognitivos dos estudantes. Neste contexto, é possível identificar a teoria de Mayer (2009) [6] sobre a importância de equilibrar as cargas cognitivas no uso de recursos multimídias.

De acordo com Mayer (2009) [6], para que a aprendizagem seja eficiente, é necessário reduzir o máximo possível o processamento cognitivo estranho, administrar o processamento cognitivo essencial e promover o processamento cognitivo generativo. Para tanto, tendo em vista os pressupostos envolvidos no processamento das informações, Mayer (2009) [6] apresenta princípios para esses fins, objetivando orientar a elaboração de materiais multimídia para o processo de ensino e aprendizagem.

Assim, entendemos que é possível estender estes princípios a atividades comuns realizadas em sala de aula a fim de poder lidar com a limitação dos canais auditivo e visual e potencializar o 
processamento cognitivo de novas ideias. Desse modo, busca-se analisar atividades comuns de sala de aula ou utilizadas em livros didáticos do $1^{\circ}$ ano do Ensino Fundamental, tomando como eixo norteador os princípios da TCAM e indicando em quais pontos elas divergem desses princípios.

\subsection{Princípios para reduzir o Processamento Cognitivo Estranho}

Princípio da Coerência: a aprendizagem ocorre de forma mais eficiente quando textos, sons e imagens que não estão relacionados com o objetivo da atividade são excluídos do material.

Vamos analisar a atividade ilustrada na Figura 1, esta tem como objetivo que, estudantes que estejam aprendendo a contar, escrevam, nos quadros abaixo dos conjuntos, os numerais que representam a quantidade de elementos em cada um dos conjuntos.
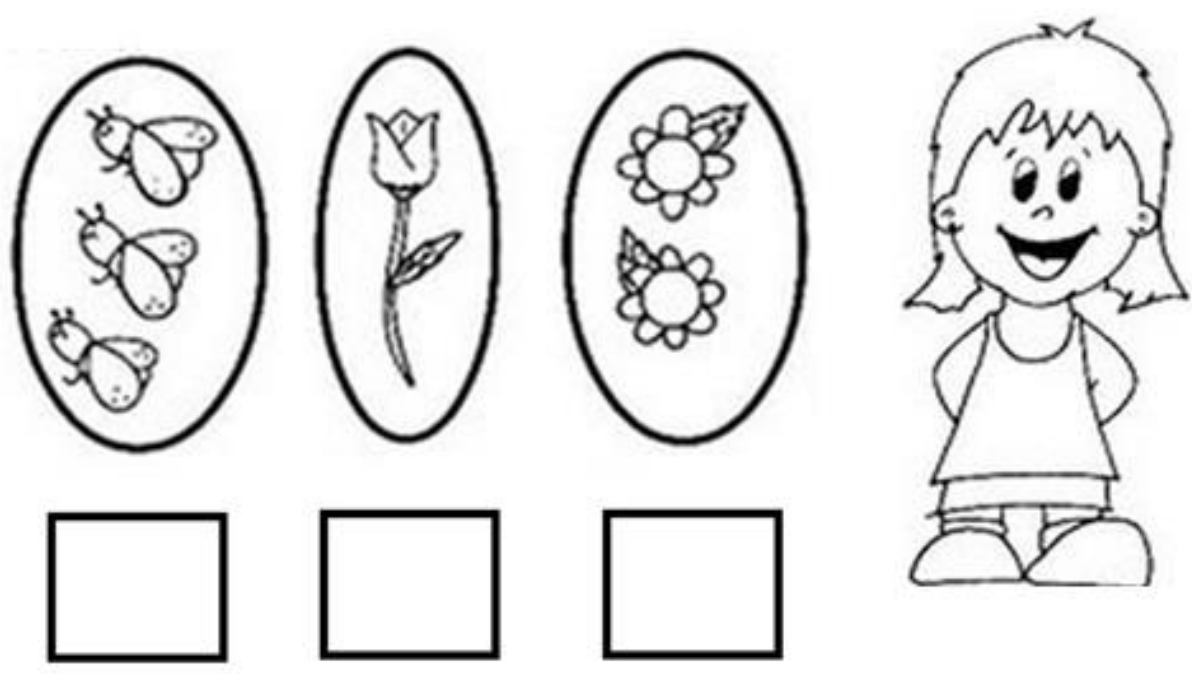

Figura 1: Atividade sobre identificação de quantidade de elementos de conjuntos. Disponível em: http://www.rota83.com/sugestoes-de-atividades-sobre-primavera.html. Acesso: 13/01/2018.

Podemos ver que esta atividade diverge do Princípio da Coerência, pois a imagem da menina não desempenha nenhuma função essencial para a execução da atividade, uma vez que o estudante pode executar a referida atividade mesmo sem a imagem da menina, o que torna essa imagem uma carga visual não essencial (estranha). Por outro lado, poder-se-ia argumentar que a presença da imagem da menina, com seu sorriso e "simpatia", tornaria a atividade mais convidativa aos estudantes. Portanto, há vários aspectos a serem levados em conta, mas, pelo aspecto da carga visual, seria mais aconselhável remover a imagem da menina da atividade. Como diretriz geral, deve-se buscar o desenvolvimento de atividades com informações claras e diretas, sem informações que possam distrair o aluno da essência da atividade.

Princípio da Sinalização: a aprendizagem ocorre de forma mais eficiente quando textos ou imagens essenciais para o objetivo da atividade forem sinalizados.

Vamos analisar a atividade ilustrada na Figura 2, em que os alunos devem observar o quadro apresentado e cobrir as linhas tracejadas que formam o numeral um.

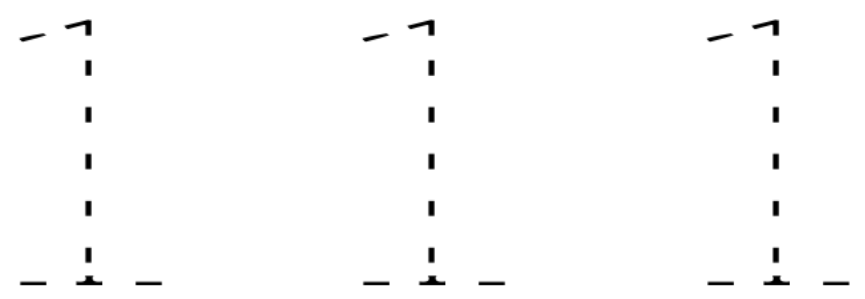

Figura 2: Atividade sobre aprender a escrever o número 1. A atividade foi construída pelos autores. 
Se considerarmos que, ao realizar essa atividade, os estudantes estão treinando o domínio da escrita do numeral 1 pela primeira vez, então eles podem não saber por onde iniciar esse processo de escrita. Assim sendo, obervamos que a referida atividade não orienta por onde o estudante deve começar a realizá-la, ou seja, por onde o estudante deve começar a cobrir as linhas tracejadas. Portanto, não apresenta uma informação que é essencial para promover o direcionamento correto para a execução da atividade. Desse modo, a atividade não estaria levando em consideração o Princípio da Sinalização. Por esse aspecto, seria aconselhável, por exemplo, indicar com setas por onde começar a cobrir as linhas tracejadas.

Princípio da Redundância: a aprendizagem ocorre de forma mais eficiente quando as informações são apresentadas por meio de imagem e narração, do que por meio de imagem, texto e narração. Isto porque o uso de textos e imagens para apresentar uma mesma informação aumenta a carga cognitiva, e pode sobrecarregar o canal visual, tendo em vista que texto e imagem são captados pelo mesmo canal.

Vamos analisar a atividade ilustrada na Figura 3, em que os estudantes devem prestar atenção aos números que serão narrados, linha a linha, pelo(a) professor(a) e, em seguida, pintar a quantidade correspondente de animais. Por exemplo, a professora lê em voz alta: "três coelhos"; então, é esperado que o estudante pinte três coelhos.

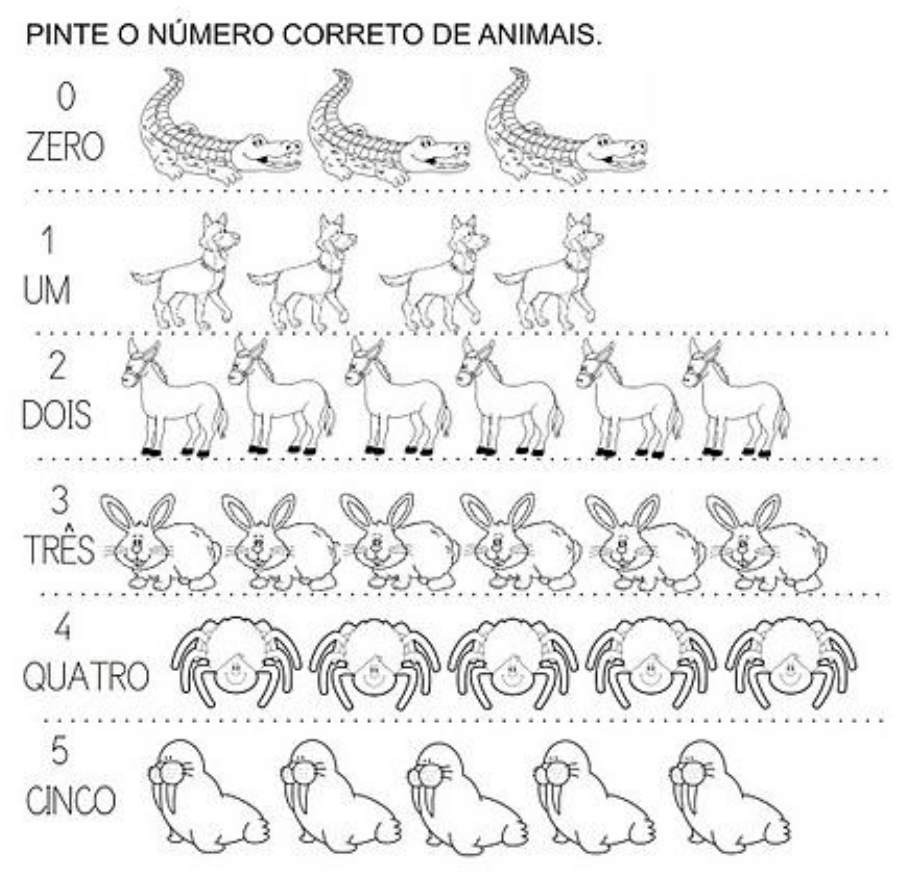

Figura 3: Atividade sobre identificação de valores dos numerais. Disponível em:

<http://altograu.blogspot.com/2012/01/atividades-de-matematica-1-ano.html>. Acesso: 13/01/2018.

Na dinâmica dessa atividade, todas as informações mencionadas (por exemplo, "três" (narrado), "3" (numeral escrito) e "TRÊS" (texto escrito)) são para apresentar uma mesma informação (quantidade de animais). Note que " 3 " (numeral escrito) e "TRÊS" (texto escrito), são efetivamente "textos" que se somam à imagem dos animais, o que pode sobrecarregar o canal visual, tendo em vista, como dito, que texto e imagem são captados pelo mesmo canal. Assim sendo, esta atividade diverge do Princípio da Redundância. Por esse aspecto, seria aconselhável que as informações fossem apresentadas por meio apenas dos numerais narrados e das imagens dos animais, ou seja, removendo da atividade os numerais escritos, pois indicar os numerais de modo escrito e narrado geraria, neste contexto, uma redundância. Noutro contexto, entretanto, poderia ser que o foco de uma dada atividade fosse justamente conectar o numeral narrado à sua representação escrita sendo que, nesse caso, a presença de ambas as representações poderia não ser considerada uma redundância. Portanto, há vários aspectos a serem levados em conta, mas, se a redundância ocorre e não contribui com o processo de aprendizagem, é aconselhável que seja removida.

Princípio da Contiguidade Espacial: a aprendizagem ocorre com maior facilidade quando textos e imagens são colocados perto um do outro no momento em que são exibidos. 
Vamos analisar a atividade ilustrada na Figura 4, em que os alunos precisam distribuir em ordem crescente os números mostrados na primeira linha abaixo da ilustração.

Observe a figura. A escada ilustrada na figura está enumerada em ordem crescente.

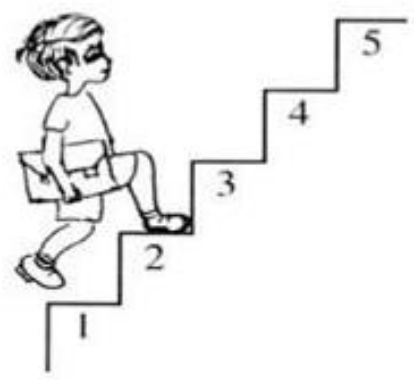

Agora distribua os números em ordem crescente em cada uma das caixas abaixo.

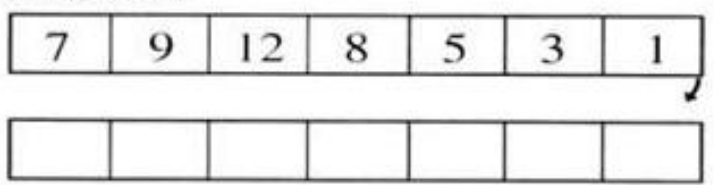

Figura 4: Atividade sobre organização de números em ordem crescente. A atividade trata-se de uma adaptação de uma atividade retirada da web. Disponivel em: <https://www.nainternet.biz/atividades-dematematica-para-1-ano-do-fundamental/>. Acesso: 13/01/2018.

Esta atividade estaria tão mais de acordo com o Princípio da Contiguidade Espacial quanto mais próximas estivessem a figura do menino subindo a escada e o texto "ordem crescente". Dito de outro modo, quanto mais a informação essencial, ordem crescente dos números, estiver distante da ilustração da mesma (no caso, a escada), maior a dificuldade para o estudante estabelecer a correlação direta entre a imagem e a informação essencial. Neste sentido, é aconselhável que o texto essencial ("ordem crescente") seja apresentado próximo à imagem, oferecendo associação imediata entre a imagem e o texto, eliminando um esforço cognitivo espúrio.

Princípio da Contiguidade Temporal: a aprendizagem ocorre de forma mais eficiente quando a imagem e a narração são apresentadas ao mesmo tempo.

Vamos analisar a atividade ilustrada na Figura 5, em que os alunos devem prestar atenção, inicialmente, para a narração do comando da questão: "Quantos ratinhos há na imagem apresentada abaixo?"; "Escreva o numeral correspondente no retângulo ao lado". Em seguida, é apresentada a ilustração na qual os estudantes irão, de fato, realizar a contagem e registrar a resposta. 


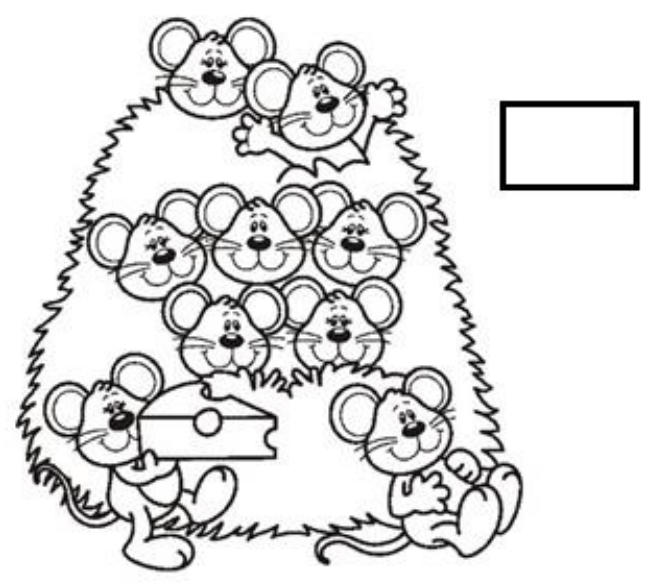

Figura 5: Atividade sobre contagem. A atividade trata-se de uma adaptação de uma atividade retirada da web. Disponível em: <http://www.ideiacriativa.org/2011/10/atividade-animais-de-jardimmatematica.html>. Acesso: 13/01/2018.

De acordo com o Princípio da Contiguidade Temporal, tal estrutura de atividade pode gerar sobrecarga na memória do estudante, pois requer que o estudante se lembre do comando da atividade, lida pelo professor anteriormente a realização da atividade. Por esse motivo, recomendase que a narração do comando da atividade e a ilustração da mesma sejam apresentadas ao mesmo tempo.

\subsection{Princípios para administrar o Processamento Cognitivo Essencial}

Princípio da Segmentação: a aprendizagem ocorre de forma mais eficiente, quando as informações são apresentadas de forma segmentada.

Vamos analisar a atividade ilustrada na Figura 6, em que o estudante deve resolver um problema de adição.

\section{Se adicionarmos mais duas maçãs na cesta, quantas maçãs teremos dentro da cesta?}

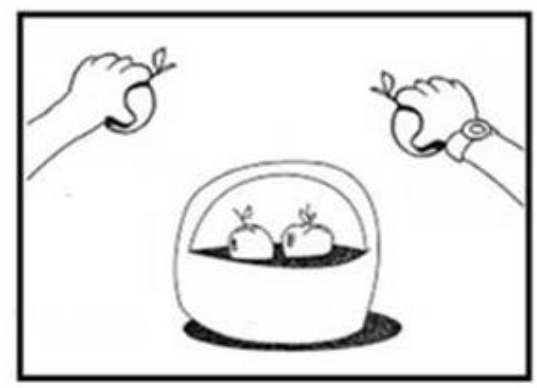

Figura 6: Atividade sobre problema de adição. A atividade trata-se de uma adaptação de uma atividade retirada da web. Disponível em:

https://rosangelaprendizagem.blogspot.com/2012/09/matematicaprobleminhasatividades.html >. Acesso: 13/01/2018.

Note-se que a atividade apresenta a informação principal para a resolução da questão "de uma só vez". Para maior clareza em relação ao que se está pedindo que o estudante resolva, bem como para facilitar a compreensão e resolução do problema, podemos considerar o Princípio da Segmentação. Assim sendo, recomenda-se que na atividade as informações sejam apresentadas em duas etapas, sendo exibidas duas imagens distintas: na primeira, serão apresentadas as maçãs 
contidas na cesta antes da adição, de modo que os estudantes poderão identificar essa quantidade; na segunda, será apresentada a imagem da adição de mais duas maçãs. Desse modo, propor a atividade em etapas, ou seja, com as informações segmentadas, pelo Princípio da Segmentação possibilita ao estudante ter maior domínio sobre a atividade. Por outro lado, para um estudante com experiência mais elevada nesse tipo de cálculo, de modo que o objetivo da atividade já seja que ele construa por si todo processo de adição, então essa segmentação pode ser reavaliada.

Princípio do Pré-treinamento: a aprendizagem ocorre de forma mais eficiente quando antes da atividade principal for realizado um treinamento, no qual é apresentando os pontos principais do conteúdo.

Vamos analisar a atividade ilustrada na Figura 7, em que os estudantes - iniciantes nesse tipo de cálculo e atividade - precisam resolver as adições. A atividade é originalmente proposta sem dar acesso a qualquer exemplo prévio de como ela deve ser realizada.

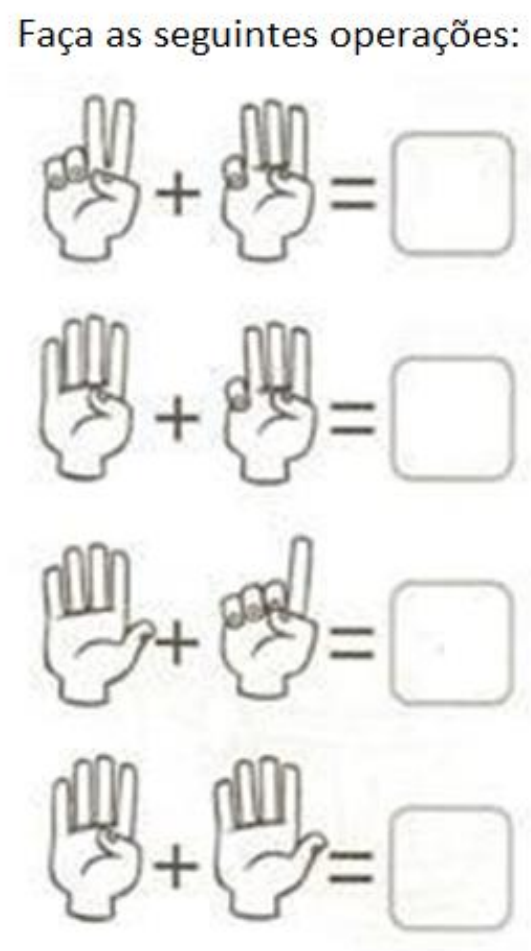

Figura 7: Atividade sobre contagem utilizando os dedos. A atividade trata-se de uma adaptação de uma atividade retirada da web. Disponível em: <https://rosangelaprendizagem.blogspot.com/p/alfabetizacaomatematica.html >. Acesso: 13/01/2018.

Nesse sentido, a aprendizagem pode ser prejudicada pela sobrecarga cognitiva necessária para compreender o mecanismo de resolução, sem a ajuda de um pré-treino. Em razão disso, recomendase que antes dos alunos iniciarem a atividade principal seja realizado um treinamento, por exemplo: o professor pode realizar algumas das questões junto com alunos, para que eles possam perceber o mecanismo de resolução para resolver o restante da atividade.

Princípio da Modalidade: a aprendizagem ocorre de maneira mais eficiente por meio de imagens e narração do que de imagens e textos, pois cada tipo de informação será processada por um canal diferente.

Vamos analisar a atividade ilustrada na Figura 8, em que temos texto escrito e imagens simultaneamente exibidos, não sendo apresentado nenhum estímulo auditivo. Os estudantes precisam identificar o número de velas que está faltando, para ter como resultado o número indicado. Consideramos, ainda, que o alvo da atividade não é o treino da leitura de textos, mas está no raciocínio matemático. 


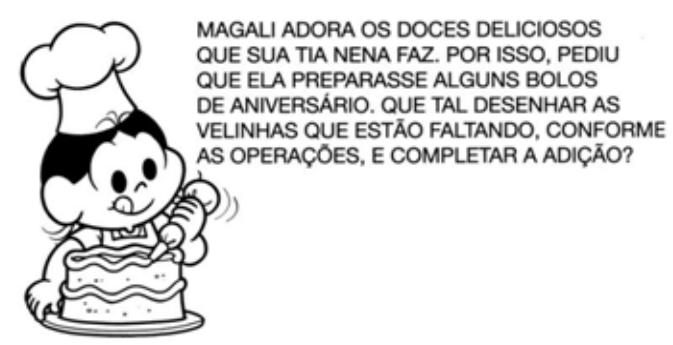

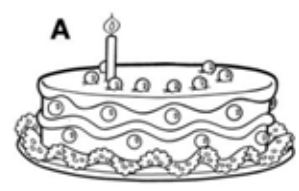

$\mathbf{1}+\square=\mathbf{5}$

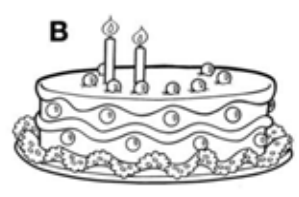

$\mathbf{2}+\square=\mathbf{5}$

Figura 8: Atividade sobre problema de adição. Disponível em: <http://www.rota83.com/atividadesturma-da-monica-numeros-e-matematica.html>. Acesso: 13/01/2018.

Da forma como está apresentada, a atividade não está de acordo com o Princípio da Modalidade, e poderá sobrecarregar o canal visual, podendo prejudicar a aprendizagem. Imagens e texto escrito são processados pelo mesmo canal. Por esse motivo, neste caso, é recomendável que a atividade seja apresentada apenas com imagem e texto narrado, ou seja, excluindo o texto escrito.

\subsection{Princípios para promover o Processamento Cognitivo Generativo}

Princípio Multimídia: a aprendizagem ocorre de maneira mais eficaz quando textos e imagens são exibidos juntos do que de forma isolada.

Vamos analisar a atividade ilustrada na Figura 9. Nesta, podemos visualizar apenas um texto, sem nenhuma imagem que possa ajudar o estudante a construir uma representação imagética mental da atividade. Vamos considerar que os estudantes sejam iniciantes nesse tipo de cálculo e atividade.

\section{Atividade}

\section{Resolva o problema:}

\section{A Magali ganhou muitos brinquedos em seu último aniversário. Ela ganhou duas bonecas, uma bola e dois ursos de pelúcia. Então, resolveu doar uma boneca e um de seus ursos. Quantos brinquedos Magali ainda têm?}

Figura 9: Atividade sobre resolução de problemas. A atividade foi construída pelos autores.

Da forma como está apresentada, a atividade não considera as orientações do Princípio Multimídia, pois somente o texto da atividade apresentada pode não ser suficiente para ajudar o estudante - iniciante, conforme considerado - a resolver o problema. Por esta razão, é recomendável que junto com o texto, sejam apresentadas imagens que correspondam à descrição da atividade. $\mathrm{O}$ objetivo, neste sentido, é ajudar aos estudantes a construir uma representação visual da atividade proposta. Em outro contexto, entretanto, pode ser que a própria construção dessa representação visual seja o alvo da atividade. 
Princípio da Personalização: a aprendizagem é mais consistente quando as informações são exibidas de forma dialógica do que formal.

Vamos analisar a atividade ilustrada na Figura 10, em que é apresentada uma atividade cujo objetivo é identificar as figuras geométricas ilustradas em um material impresso, associando as figuras geométricas aos seus respectivos nomes. Vamos considerar, ainda, que os estudantes sejam iniciantes nesse tipo de identificação e de leitura.

\section{Observe a imagem abaixo, cada caixa possui um nome diferente. Ligue cada uma das formas geométricas às suas respectivas caixas nomeadas.}
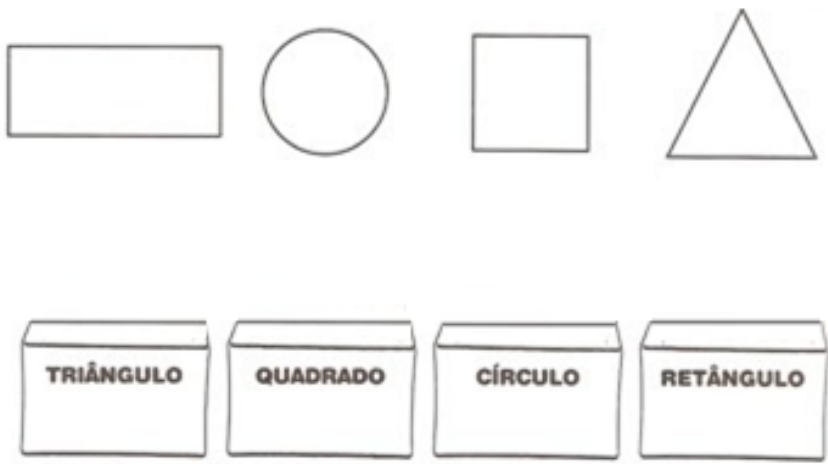

Figura 10: Atividade sobre identificação de formas geométricas. A atividade trata-se de uma adaptação de uma atividade retirada da web. Disponível em: <http://tiahelainy.blogspot.com.br/2011/01/algumasatividades-de-matematica.html>. Acesso: 17/01/2018.

O comando é apresentado com uma linguagem bastante formal, pouco acessível à compressão dos estudantes. Neste sentido, é aconselhável apresentar o comando da atividade no estilo de "conversação informal".

Princípio da Voz: aprende-se com maior facilidade quando a narração é apresentada com uma voz humana natural do que por meio de uma voz "mecanizada”. É válido ressaltar que este princípio só é aplicável ao uso de certos recursos tecnológicos.

Vamos analisar a atividade ilustrada na Figura 11, em que temos um jogo hipotético de perguntas e respostas, cujo objetivo é a contagem de objetos apresentados na tela. Para iniciar a atividade, os estudantes devem clicar no ícone de alto-falante para ativar a narração do comando da atividade. Entretanto, a voz é "computadorizada".
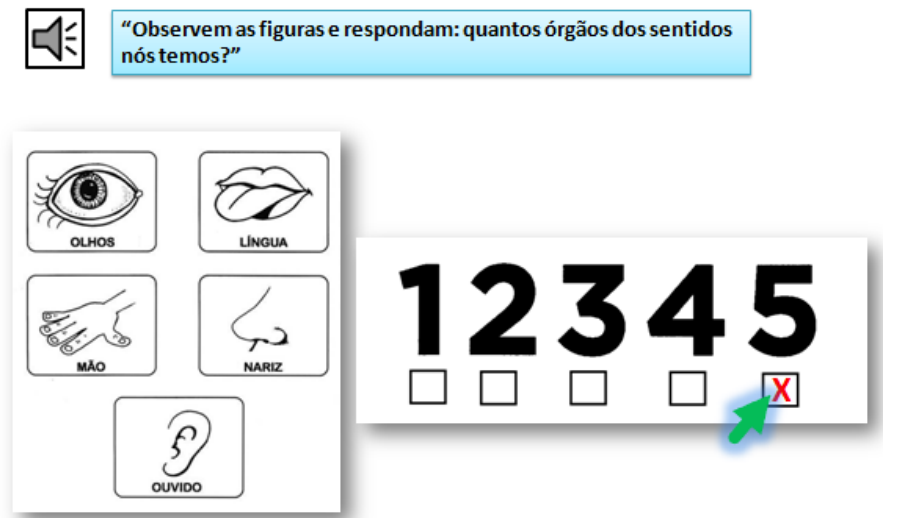

Figura 11: A atividade sobre contagem. A atividade trata-se de uma adaptação de uma atividade retirada da web, bem como as imagens contidas na mesma: disponível em: < https://soatividades.com/atividadessobre-os-sentidos-para-educacao-infantil > Acesso: 17/01/2018; disponível em: <

http://carlosdrummond1.blogspot.com/2013/05/trabalhando-com-o-texto.html>Acesso: 17/01/2018. 
A atividade construída dessa forma não está de acordo com o Princípio da Voz, pois a forma como é usada a voz e suas especificidades pode repercutir na condição emocional do estudante. Portanto, é recomendável que, na atividade, a voz computadorizada seja substituída por uma voz humana.

Princípio da Imagem: a aprendizagem não ocorre necessariamente melhor com o uso de personagens falantes apresentados na instrução Multimídia. É válido ressaltar que este princípio só é aplicável no uso de certos recursos tecnológicos.

Vamos analisar a atividade ilustrada na Figura 12, nesta ilustramos um jogo hipotético que tem como objetivo completar os potes inserindo bolinhas, cujas somatórias dos valores que estas representam seja o numeral exibido ao lado dos potes. Para iniciar a atividade, os estudantes devem clicar no ícone de alto-falante para ativar a narração do comando da atividade. Após a narração, há a presença de um personagem que fala "Então, mãos à obra!".

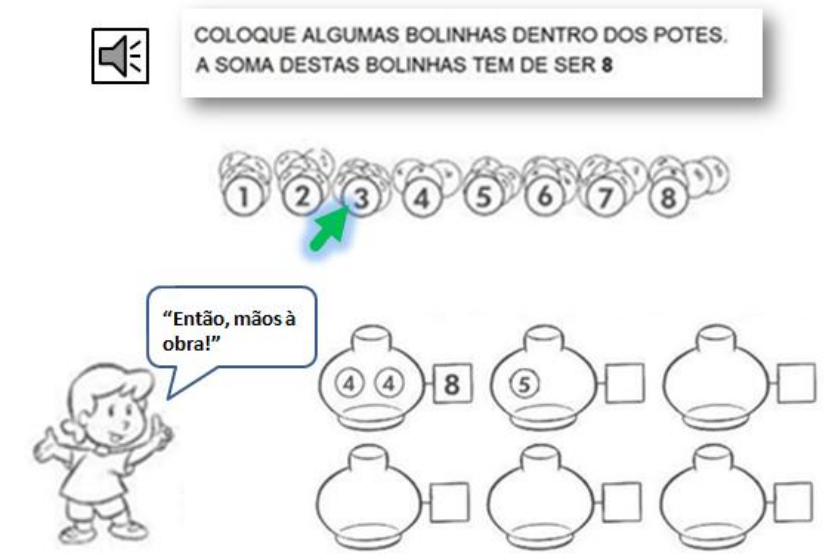

Figura 12: Atividade de adição. A atividade trata-se de uma adaptação de uma atividade retirada da web. Disponível em: <http://tudosetransformaeducando.blogspot.com/2012/10/atividades-de-alfabetizacaomatematica.html >. Acesso: 17/01/2018.

A presença do "personagem falante" na atividade pode desviar a atenção dos estudantes, resultando em um processamento cognitivo estranho no decorrer da aprendizagem, o que não está de acordo com o Princípio da Imagem. Ou seja, mesmo sem a fala da personagem, o estudante pode executar a referida atividade. Por esse aspecto, seria aconselhável remover a personagem e sua fala. $\mathrm{Ou}$, de outro modo, que a personagem apresente, além do incentivo a executar a atividade, informações relevantes para a resolução da mesma. Por exemplo, a personagem poderia apresentar o comando da atividade, ou ainda, oferecer dicas de como resolver a questão proposta.

\section{CONCLUSÃO}

O conhecimento sobre como se dá o processamento cognitivo precisa fazer parte do desenvolvimento das práticas pedagógicas. Desse modo, tal conhecimento deve fazer parte da realidade do processo de ensino e aprendizagem nas séries iniciais, tendo em conta que é nesta etapa que os estudantes estão sendo alfabetizados e letrados. Portanto, todo conhecimento construído nesta etapa da formação escolar influenciará no desempenho dos estudantes nas próximas etapas de sua formação. Assim, também é possível perceber que, independentemente do tipo de material, sendo eletrônico ou não, a forma como são exibidas as informações visuais ou auditivas durante a execução das atividades em sala de aula é determinante no desempenho dos estudantes. A Teoria Cognitiva da Aprendizagem Multimídia pode ser considerada bastante interessante para a orientação ao desenvolvimento de estratégias pedagógicas para a realização de atividades em sala de aula, haja vista que esta estabelece princípios que permitem a elaboração de materiais educativos, levando em consideração a construção das estruturas cognitivas para o desenvolvimento do aprendizado. 


\section{AGRADECIMENTOS}

Os autores agradecem a Jeferson Danilo Lima Silva, France Fraiha Martins e Alessandra Nascimento Braga pela leitura de versões prévias deste trabalho, bem como por valiosas discussões e sugestões.

\section{REFERÊNCIAS BIBLIOGRÁFICAS}

1. Santos LMA, Tarouco MR. A importância do estudo da teoria da carga cognitiva em uma educação tecnológica. Renote. 2007;5(1):1-9, doi: 10.22456/1679-1916.14145.

2. Baddeley A, Eysenck AW, Anderson MC. Memory. New York: Psychology Press; 2009. 531 p.

3. Feldman RS. Introdução à psicologia. Amgh Editora, 2015. 165 p.

4. Souza N. Teoria da carga cognitiva: origem, desenvolvimento e aplicações [Dissertação]. Belém: Universidade Federal do Pará; 2010. 173 p.

5. Miller G. The magical number seven, plus or minus two: some limits on ourcapacity for processing information. Psyc Rev. 1994;101(2):343-352, doi: 10.1037/0033-295x.101.2.343.

6. Mayer RE. Multimedia learning. Second edition. Santa Barbara: University of California; 2009. 304 p.

7. Schnotz W, Lowe R. External and internal representations in multimedia learning. Learning and Instruction. 2003;13(2):117-23, doi:10.1016/S0959-4752(02)00015-4.

8. Sweller J, Ayres P, Kalyuga S. Cognitive load theory. New York: Springer; 2011. 274 p. 